\title{
Modelling the evolution in microchemistry and its effects on the softening behavior of cold rolled AlFeMnSi-alloys during annealing
}

\author{
Emmanuel Hersent ${ }^{1, a}$, Ke Huang ${ }^{1, b}$, Jesper Friis ${ }^{2, c}$, and Knut Marthinsen ${ }^{1, d}$ \\ ${ }^{1}$ Department of Materials Science and Engineering, NTNU, NO-7491, Trondheim, Norway \\ ${ }^{2}$ SINTEF Materials and Chemistry, NO-7465, Trondheim, Norway \\ aemmanuel.hersent@material.ntnu.no, bke.huang@ntnu.no, cjesper.friis@sintef.no, \\ ${ }^{d}$ knut.marthinsen@material.ntnu.no
}

Keywords: precipitation, recrystallization, modeling, concurrent precipitation

\begin{abstract}
A dedicated diffusion controlled precipitation model for AlMnFeSi-alloys, based on classical nucleation and growth theory, has been implemented and coupled to a phenomenological softening model accounting for the combined effect of recovery and recrystallization during annealing after cold rolling. The result is a fully coupled precipitation and softening model which in principle is capable of predicting for variations in solute levels and size and volume fraction of dispersoids and their interaction with the softening behavior during annealing.
\end{abstract}

\section{Introduction}

AA3xxx aluminium alloys, containing $\mathrm{Mn}$ as the main alloying element are widely used in packaging and architecture industry. These alloys are recognized to be highly cost effective and combine good corrosion properties and formability with moderate strength. The last two properties are mainly controlled by the grain structure/size in the material and show opposite trends with increasing grain size: mechanical strength decreases whereas the material becomes less subject to corrosion. Depending on the targeted applications a compromise between these two properties has to be made by controlling the softening behavior. The final grain structure results from the recovery/recrystallization behavior during the final heat treatment after cold rolling and is often strongly influenced by concurrent precipitation. The solute still in solid solution may precipitate inside grains and/or on subgrain/grain boundaries, hindering their migrations and leading then to slow kinetics and coarse grains. So the ability to simulate concurrent precipitation is of major industrial interest. First, the precipitation and recrystallization model will be briefly introduced, afterwards their coupling very shortly described and finally applied on a generic test case.

\section{Precipitation model}

The precipitation model aims to simulate the precipitation kinetics of the two main phases in AA3xxx type alloys: $\mathrm{Al}_{6}(\mathrm{Fe}, \mathrm{Mn})$ and $\mathrm{Al}_{17}(\mathrm{Fe}, \mathrm{Mn})_{4} \mathrm{Si}_{2}$. The model is based on the discretization of the radius distribution for each type of precipitate and the determination of the precipitate number density in each class is performed at each time step [1]. The particle size distribution $\varphi$ is governed by the partial differential equation:

$$
\frac{\partial \varphi}{\partial t}=-\frac{\partial}{\partial r}(\mathrm{v} \varphi)+j
$$

with $\mathrm{v}$ the growth rate of the precipitates and $j$ the nucleation rate. As the precipitates are nonstoichiometric, it is necessary to track how the precipitate chemistry changes with time. It is achieved by introducing a new distribution $\varphi_{F e}$ which determines the number of iron atoms trapped in the precipitates of size $r$ and $r+d r$ and is governed by the following partial differential equation: 


$$
\frac{\partial \varphi_{F e}}{\partial t}=-\frac{\partial}{\partial r}\left(\mathrm{v} \varphi_{F e}\right)+\frac{4 \pi r^{2} n}{(m+n+p) v_{a t}^{P}} f_{F e}^{\mathrm{int}} \varphi+S
$$

with $\mathrm{m}, \mathrm{n}$ and $\mathrm{p}$ the stoichiometric numbers respectively for $\mathrm{Al}$, atomic sites for $\mathrm{Fe}$ and $\mathrm{Mn}$, and $\mathrm{Si}$, $v_{a t}^{P}$ the mean atomic volume inside the precipitates, $f_{F e}^{\text {int }}$ the fraction of Fe, Mn sites occupied by iron atoms at the interface matrix/precipitates. Eq. 2 has an additional source term $\frac{4 \pi r^{2} n}{(m+n+p) v_{a t}^{P}} f_{F e}^{\text {int }} \varphi$ compared to Eq. 1 to take into account that during the growth/dissolution of precipitates iron atoms are absorbed/released from/to the solid solution. The expression of this source term is based on the assumption that all precipitates in the same size class have the same chemical composition $f_{F e}^{P}$. Then the "chemical" class distribution $\varphi_{F e}$ scales with the size class distribution $\varphi$ :

$$
\varphi_{F e}(r, t)=\frac{4 \pi r^{3}}{3 v_{a t}^{P}} \frac{n}{(m+n+p)} f_{F e}^{P}(r) \varphi(r, t)
$$

To perform the calculation of the evolution of $\varphi$ and $\varphi_{F e}$ with time, the velocity of the precipitates must be determined. First, local equilibrium at the interface matrix/precipitates will be assumed maintained. To be able to calculate interfacial concentrations without the help of a thermodynamic software (like Thermo-Calc [2]), a simplified thermodynamic description of the system is used: the aluminium solid solution is supposed regular and the precipitates $\mathrm{Al}_{6}(\mathrm{Fe}, \mathrm{Mn})$ and $\mathrm{Al}_{17}(\mathrm{Fe}, \mathrm{Mn})_{4} \mathrm{Si}_{2}$ an ideal solid solution of their end-members phases. It has been demonstrated that these two assumptions give a reasonable description of phase diagrams in the Al rich corner [3]. Then the interfacial concentrations must fulfill the following solubility products [4]:

$$
\begin{aligned}
& \left(x_{F e}^{i}\right)^{n}\left(x_{S i}^{i}\right)^{p}=\left(f_{F e}^{i}\right)^{n} K_{\mathrm{Al}_{\mathrm{m}} \mathrm{Fe}_{\mathrm{n}} \mathrm{Si}_{\mathrm{p}}}^{i} \text { with } K_{\mathrm{Al}_{\mathrm{m}} \mathrm{Fe}_{\mathrm{n}} \mathrm{Si}_{\mathrm{p}}}^{i}=K_{\mathrm{Al}_{\mathrm{m}} \mathrm{Fe}_{\mathrm{n}} \mathrm{Si}_{\mathrm{p}}}^{e q} e^{\frac{2 \gamma(m+n+p) v_{a t}^{P}}{r k_{B} T}} \\
& \left(x_{M n}^{i}\right)^{n}\left(x_{S i}^{i}\right)^{p}=\left(1-f_{F e}^{i}\right)^{n} K_{\mathrm{Al}_{\mathrm{m}} \mathrm{Mn}_{\mathrm{n}} \mathrm{Si}_{\mathrm{p}}}^{i} \text { with } K_{\mathrm{Al}_{\mathrm{m}} \mathrm{Mn}_{\mathrm{n}} \mathrm{Si}_{\mathrm{p}}}^{i}=K_{\mathrm{Al}_{\mathrm{m}} \mathrm{Mn}_{\mathrm{n}} \mathrm{Si}_{\mathrm{p}}}^{e q} e^{\frac{2 \gamma(m+n+p) v_{a t}^{P}}{r k_{B} T}}
\end{aligned}
$$

The $\exp \left(2 \gamma(m+n+p) v_{a t}^{P} / r k_{B} T\right)$ is the Gibbs-Thomson factor that describes the influence of precipitate curvature on interfacial concentrations. The last two relationships do not define univocally the interfacial compositions. Therefore, an additional constraint is required, which is that the diffusion flux of every element towards (or away from) the interface must be such that the interface velocity is the same regardless of which element is considered:

$$
\frac{d r}{d t}=\frac{D_{F e}}{r} \frac{x_{F e}^{s s}-x_{F e}^{i}}{x_{F e}^{P}-x_{F e}^{i}}=\frac{D_{M n}}{r} \frac{x_{M n}^{s s}-x_{M n}^{i}}{x_{M n}^{P}-x_{M n}^{i}}=\frac{D_{S i}}{r} \frac{x_{S i}^{s s}-x_{S i}^{i}}{x_{S i}^{P}-x_{S i}^{i}}
$$

with $x_{F e}^{P}, x_{M n}^{P}, x_{S i}^{P}$ the atomic fraction of Fe, Mn and Si inside the precipitates corrected by a factor taking into account that the mean atomic volume inside the precipitate $v_{a t}^{P}$ is different from the mean atomic volume in solid solution. 


\section{Recovery and Recrystallization Model}

Only a short overview of this model (nicknamed AlSoft) will be given because it has been covered thoroughly in previous articles [5-7]. In this model these phenomena are reduced to the evolution of three variables: the mean subgrain size $\delta$, the dislocation density inside subgrains $\rho_{i}$, and the radius of the recrystallized grain $\mathrm{r}$. Upon annealing, dislocations stored during the process of deformation will be annihilated and rearranged in low energy patterns (low angle boundaries). The reaction rate of these two mechanisms is mainly set by dislocation velocity which in our treatment is assumed controlled by solute drag. Then the evolutions with time of $\rho$ and $\delta$ take the form:

$$
\begin{aligned}
& \frac{d \rho_{i}}{d t}=-v_{D} b A_{\rho} B_{\rho}\left(\rho_{i}(t)\right)^{3 / 2} e^{-\frac{U_{a}(t)}{R T}} 2 \sinh \left(\frac{A_{\rho} G b^{4}}{k T(t)} \sqrt{\rho_{i}(t)}\right), A_{\rho}=\omega_{\rho} c_{s s}^{-e_{\rho}} \\
& \frac{d \delta}{d t}=v_{D} b A_{\delta} B_{\delta} e^{-\frac{U_{a}(t)}{R T}} 2 \sinh \left(\frac{A_{\delta} G b^{4}}{k T(t)} \frac{1}{\delta(t)}\right), A_{\delta}=\omega_{\delta} c_{s s}^{-e_{\delta}}
\end{aligned}
$$

Here $G$ is the shear modulus, $b$ is Burgers vector $v_{D}$ is the Debye frequency, $k$ is Bolzmann's constant, $\omega_{\rho, \delta}$ and $e_{\rho, \delta}$ are model parameters, and $B_{\rho, \delta}$ alloy specific fitting constants. $c_{s s}$ is an effective level of solute and $U_{a}$ an activation energy, which in the case of solute drag equals that of diffusion of solutes.

The arrangement of dislocations and subgrains is the driving force $P_{D}$ for the grain boundary migration of the recrystallized grains:

$$
P_{D}=0.3 \frac{\gamma_{S G B}}{\delta(t)}+\frac{1}{2} G b^{2} \rho_{i}(t)
$$

with $\gamma_{S G B}$ the interfacial energy of the subgrain boundaries. During its migration, the grain boundary is hindered by second-phase particles and solute atoms and then moves at a velocity $\mathrm{V}$ :

$$
V=d r / d t=M(t)\left(P_{D}(t)-P_{Z}(t)\right)
$$

with $M(t)$ the extrinsic mobility of the grain boundary resulting from the drag of the solute atoms $M(t)=M_{0} / R T c_{s s}(t) \exp \left(U_{X} / R T\right)$ and $P_{Z}(t)=\frac{3}{2} \gamma_{G B} \frac{f_{v}}{r_{m}}$ the Zener drag where $c_{s S}, r_{m}$ and $f_{v}$ are obtained from the precipitation model $\left(r_{m}=\int_{0}^{\infty} r \varphi(r) d r\right.$ and $\left.f_{v}=\int_{0}^{\infty} \frac{4}{3} \pi r^{3} \varphi(r) d r\right)$,

The nucleation of recrystallized grains is covered elsewhere in the literature [7].

\section{Coupling between the two models}

The actual softening behavior results from the interaction between recrystallization and precipitation. As high angle boundaries are favorable sites for nucleation of $\alpha$-precipitates, $\alpha$ precipitates will nucleate preferably on them leading to pinning and a slowing down of its migration. The interaction between the two phenomena is simulated by running consecutively the precipitation model and the softening model (through a strong coupling) at each small time steps and by exchanging the updated values of the relevant state variables needed $\left(\rho_{i}, \delta, X_{r e x}, D_{r e x}, c_{s s}, r_{m}, f_{v}\right)$ by the respective models at the beginning of each time step. 


\section{Model Predictions}

Model calculations have been carried out by assuming an initial deformed structure with $\rho=9.510^{13} \mathrm{~m}^{-2}$ and $\delta=0.32 \mu \mathrm{m}$ and an initial precipitation state with $\mathrm{Al}_{6}(\mathrm{Fe}, \mathrm{Mn})$ constituents having a $f_{v}=2.72 \%$ and $r_{m}=1500 \mathrm{~nm}$ and $\mathrm{Al}_{17}(\mathrm{Fe}, \mathrm{Mn})_{4} \mathrm{Si}_{2}$ dispersoids having a $f_{v}=0.05 \%$ and $r_{m}=20 \mathrm{~nm}$ The evolution in recrystallized fraction and grain size for two different isothermal treatments at $300^{\circ} \mathrm{C}$ and $325^{\circ} \mathrm{C}$ have been calculated and plotted on Fig. 1a). For comparison, the softening model has been run without any coupling with the precipitation model, and the results have been plotted on Fig.1b). For both temperatures it is seen that with concurrent precipitation recrystallization is retarded, and at the lower temperature even stopped before complete recrystallization due the Zener drag $P_{Z}$ becoming larger than the driving pressure $P_{D}$. The grain size, however, is barely not affected in these particular cases, as site saturation is assumed and concurrent precipitation only influence growth.

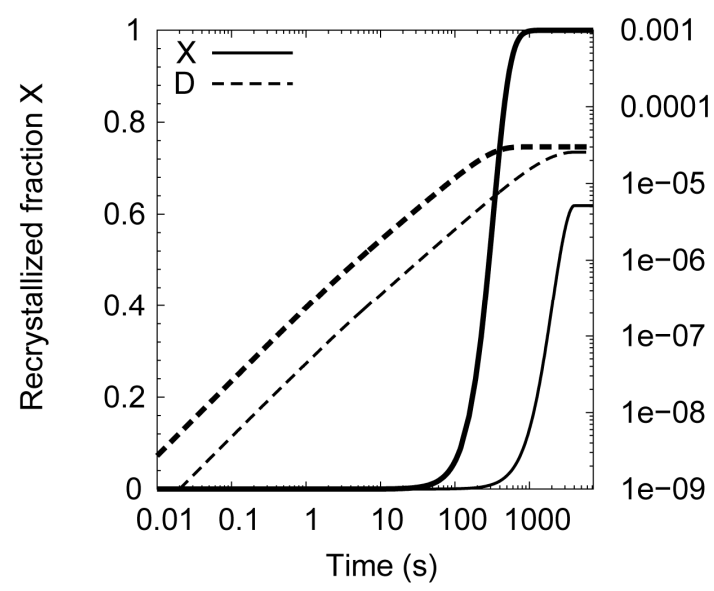

(a)

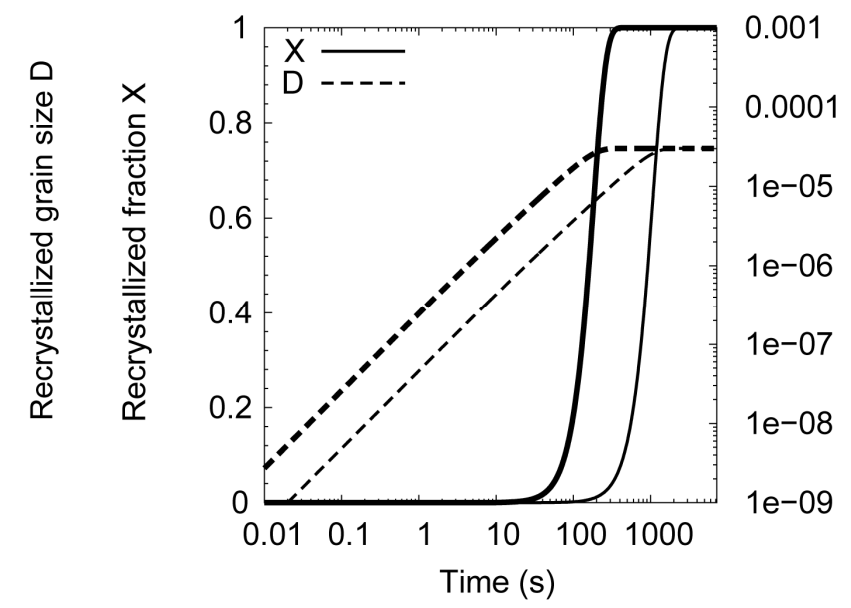

(b)

Fig 1: Evolution of the recrystallized fraction and grain size at $300^{\circ} \mathrm{C}$ (thin lines) and $325^{\circ} \mathrm{C}$ (thick lines) (a) when the two models are coupled and (b) when the recrystallization model is run alone with the same initial conditions.

\section{Conclusion}

A recovery and recrystallization model and a precipitation model have been coupled together to simulate concurrent precipitation occurring during back-annealing of AA3xxx type alloys. Some very preliminary results have demonstrated that key aspects of this phenomenon, like the slowing down the kinetics of the recrystallization process are reproduced.

\section{References}

[1] O.R. Myhr, Ø. Grong, Acta Materialia 48 (2000) 1605-1615.

[2] J.O. Andersson, T. Helander, L. Höglund, P. Shi, B. Sundman, Calphad, 26 (2002) 273-312.

[3] C. Sigli, R. Shahani, Applications of multicomponent phase diagrams to aluminum alloys, Japan Inst Metals, Sendai, 1999.

[4] A. Hakonsen, D. Mortensen, S. Benum, T. Pettersen, T. Furu, in: W.A. Schneider (Ed.) Light Metals 2002, Minerals, Metals \& Materials Soc, Warrendale, 2002, pp. 793-800.

[5] O. Engler, L. Löchte, J. Hirsch, Acta Materialia 55 (2007) 5449-5463.

[6] J.A. Sæter, B. Forbord, H.E. Vatne, E. Nes, in: Proceedings 6th International Conference on Aluminum Alloys, ICAA-6 eds., JILM, Japan, 1998, pp. 113-126.

[7] H.E. Vatne, T. Furu, R. Ørsund, E. Nes, 44 (1996) 4463-4473. 


\section{Recrystallization and Grain Growth V}

10.4028/www.scientific.net/MSF.753

Modelling the Evolution in Microchemistry and its Effects on the Softening Behavior of Cold Rolled AlFeMnSi-Alloys during Annealing

10.4028/www.scientific.net/MSF.753.143

\section{DOI References}

[1] O.R. Myhr, Ø. Grong, Acta Materialia 48 (2000) 1605-1615.

http://dx.doi.org/10.1016/S1359-6454(99)00435-8

[5] O. Engler, L. Löchte, J. Hirsch, Acta Materialia 55 (2007) 5449-5463.

http://dx.doi.org/10.1016/j.actamat.2007.06.010 